\title{
ПРИНЦИПЫ ПРИРОДОИНТЕГРАЦИИ В ФОРМИРОВАНИИ АРХИТЕКТУРНОЙ СРЕДЫ СОВРЕМЕННЫХ ОБЪЕКТОВ ЗДРАВООХРАНЕНИЯ
}

Скороходова Алина Валерьевна, ХНУСА, заведующая кафедры ДАС, кандидат архитектуры, Родик Янина Сергеевна, ХНУСА, доцент кафедры ДАС, кандидат архитектуры, Даниленко Евгений Леонидович, ХНУСА, дочент кафедры ДАС, кандидат архитектуры,

Украина

DOI: https://doi.org/10.31435/rsglobal_ws/31032019/6402

\section{ARTICLE INFO}

Received: 15 January 2019

Accepted: 23 March 2019

Published: 31 March 2019

\section{KEYWORDS}

architectural environment, nature integration, modern healthcare facilities, landscape therapy. \begin{abstract}
The relevance of health facilities formation taking into account principles of nature integration is substantiated in the article. It is shown that the concept of harmonious interaction with nature gives the best results for treatment and rehabilitation of patients; it gains more popularity and attracts attention of specialists in the field of medicine, architecture and design around the world. On the basis of the research work, several principles of nature integration in formation of architectural environment of health facilities can be distinguished. They depend on functional purpose of architectural objects, compositional structure, climatic conditions, ecosystem and location. It is proved that architectural formation of health facilities harmoniously associated with natural environment directly affects health of patients. In the process of architectural environment formation it is very important to take into account interests of environment users and nature itself, in order to obtain a favorable result of interaction of natural environment and man. Taking into account principles of nature integration in the design of health facilities contributes to improving the quality of medical and rehabilitation institutions environment, raising the level of services provided and harmonizing the environment.
\end{abstract}

Citation: Скороходова А. В., Родик Я. С., Даниленко Е. Л. (2019) Principy Prirodointegracii v Formirovanii Arhitekturnoj Sredy Sovremennyh Ob'ektov Zdravoohraneniya. World Science. 3(43), Vol.1. doi: 10.31435/rsglobal_ws/31032019/6402

Copyright: (C) 2019 Скороходова А. В., Родик Я. С., Даниленко Е. Л. This is an open-access article distributed under the terms of the Creative Commons Attribution License (CC BY). The use, distribution or reproduction in other forums is permitted, provided the original author(s) or licensor are credited and that the original publication in this journal is cited, in accordance with accepted academic practice. No use, distribution or reproduction is permitted which does not comply with these terms.

Введение. Здравоохранение является одной из основных сфер, определяющих качество жизни людей и социальное самочувствие общества. Непрерывное совершенствование методов и средств диагностики и лечения, внедрение новой медицинской аппаратуры и оборудования, возникновение новых, ранее неизвестных лечебно-диагностических отделений и вспомогательных служб, применение новых форм организации медицинского обслуживания приводит к изменению содержания, мощности, а иногда и профиля существующих учреждений здравоохранения. Эти изменения, в свою очередь, требуют адаптации архитектурной среды к новым потребностям.

Медицинские и реабилитационные центры и комплексы входят в число наиболее сложных типов учреждений с точки зрения проектирования и архитектуры, поскольку должны не только осуществлять диагностику, лечение и восстановление пациентов, решать административнохозяйственные задачи, предоставлять комфортные условия для пациентов, но и отвечать различным нормативам противопожарной безопасности и санитарно-эпидемиологическим требованиям. Долгое время функциональность считалась определяющим критерием при проектировании объектов здравоохранения, однако в последнее десятилетие архитекторы Европы и Америки совершили прорыв в этой области, доказав, что продуманные архитектура и дизайн, не в ущерб функциональности, в большей степени влияют на состояние пациента и работу врачей, чем было 
принято считать ранее. Специалисты сходятся во мнении, что будущее за зданиями и комплексами, внешний вид которых скорее напоминает жилое помещение, чем больницу в нашем традиционном представлении. Тони Монк, британский архитектор, специализирующийся на дизайне в области здравоохранения, считает, что «окружающая среда больницы способствует лечению пациентов» [4].

Идея полностью очевидна: привлекательное сооружение, госпиталь с мягким освещением, вдохновляющими видами из окон, изогнутыми коридорами, садами, красивым ландшафтом и произведениями искусства, создают комфортную среду для лечения и реабилитации. Пациенты в таких больницах быстрее будут выздоравливать, а врачи будут исполнять свои обязанности лучше.

«Люди мысленно уязвимы, когда они входят в больницу», утверждает Тони Монк, «и если они сбиты с толку ужасным, страшным, бетонным, неинтересным, плохим помещением в жутких цветах, это принуждает их чувствовать себя еще хуже» [4]. Архитекторы проводят все новые и новые исследования с целью поиска поддержки своих проектов. Например, по их расчетам пациенты идут на поправку намного быстрее, если из окон им открывается вид на какой-либо прекрасный сад, чем на бесчисленное количество автомобилей.

Важно отметить, что у таких объектов здравоохранения экономическая эффективность намного более высока, чем у зданий старого образца, где акцентировалась функциональная сторона, а не ощущение. В центр по проектированию здоровья (калифорнийская организация, которая поддерживает идею больниц, «содействующих выздоровлению») было подсчитано, что реализация подобных изменений прибавила бы 12 млн. дол. к общей стоимости проекта 240 млн дол., рассчитанного на 300 чел.

Результаты исследования. За последние десятилетия стремительно развиваться различные объекты здравоохранения, это нашло отражение в новых архитектурных формах, инженерных и медицинских технологиях, новом подходе к дизайну. Лечебные здания перестали быть закрытыми «местами боли и страдания», а наоборот они превращаются все более открытые, современные «дворцы надежды и здоровья». В странах Европы и Америки строится большое количество зданий различных по форме и дизайну, что, кажется, невозможно найти в них что-то общее. Но во всех этих зданиях воплощаются представления о том, какие должны быть современные объекты здравоохранения человека, взаимодействия природы и архитектуры, а также влияния природной среды на оздоровление пациентов.

По словам известного итальянского архитектора Джо Понти, «архитектура должна служить счастью и потребностям людей на уровне их физической жизни... Должна питать человеческий разум на уровне культурного развития. Как искусство архитектура должна питать душу человека и его мечты...» [3]. Если сказанное отнести к архитектуре объектов здравоохранения, ее роль значительно возрастет, так как имеет влияние на людей с повышенным психоэмоциональным восприятием окружающей среды.

При проектировании и строительстве медицинских и реабилитационных зданий учитывается целый комплекс условий и требований. И одно из основных это природноклиматические условия, влияющие на архитектурно-планировочные решения зданий и комплексов. Выделяются следующие: климатические (температура воздуха, влажность воздуха, ветровой режим и т.д.); геологические и геоморфологические условия.

Климатические условия места строительства объектов здравоохранения оказывают существенное влияние на планировочные решения, архитектурный облик зданий. Более полный учет природно-климатических условий в архитектурном проектировании, направлены на улучшение микроклимата и композиционно-художественной выразительности зданий является существенным резервом повышения качества архитектуры. Обеспечение в зданиях благоприятной среды для деятельности людей, их культурно-бытового обслуживания, а также проведение специальных оздоровительных мероприятий имеет большое значение. Климат, рельеф, элементы ландшафта выступают в качестве объективной предпосылки для создания индивидуального архитектурно-художественного образа конкретного здания или комплекса.

Рельеф местности также имеет большое влияние на формирование объемнопланировочной структуры медицинских зданий. При этом решается двойная задача техническая и архитектурно-художественная. Технической стороной задачи является рациональное использование рельефа местности для наиболее удобного и экономичного размещения всех элементов здания. В архитектурно-художественном решении здания формируется связь его объемно-пространственной структуры с окружающей средой, ландшафтом. Использование рельефа участка обогащает композицию. Здание или комплекс зданий, размещенное на рельефе, позволяет организовать в разных уровнях технологические процессы, которые нежелательно совмещать, например, прием больных и движение посетителей. 
В частности, целесообразно при соответствующем обосновании создание искусственного рельефа, однако при этом следует избегать излишних перепадов планировочных отметок.

На данном этапе все больше внимания уделяется разработке архитектурных объектов, связанных с естественной средой, внесению природных элементов в создание архитектуры, уменьшение влияния индустриальной застройки. Объекты здравоохранения особенно нуждаются в природоинтегрированном подходе к проектированию архитектурной среды, ведь доказано, что люди, которые лечатся или восстанавливаются после болезней, в естественной среде, обладают более эмоциональным самочувствием, обеспечивается атмосфера спокойствия, безмятежности, и, в итоге, бесценное исцеление.

Огромное значение в создании комфортных микроклиматических условий в помещениях и окружающей здание среде принадлежит озеленению. Зеленые насаждения на территории медицинских и реабилитационных комплексов оздоравливают и регулируют микроклимат, защищают помещения от перегрева, являются средством защиты от прямых солнечных лучей, задерживают ветровые потоки и распространение уличных шумов, собирают на листве значительное количество аэрозолей, представляя собой «зеленый фильтр», поднимают жизненный тонус человека. Микроклиматическая роль озеленения заключается в его влиянии на радиационный режим, температуру, влажность и состав воздуха, на движение ветровых потоков [2].

В современном мире проектирование объектов здравоохранения, ориентировано на пациентов, так как до этого времени здания проектировались исключительно опираясь на потребностей организации работы персонала [2]. Исходя из этого в странах Европы и Америки основными тенденциями, если позволяет участок для проектирования, является снижение этажности больничных зданий до уровня «человеческого размера» проектирование малоэтажных корпусов «вровень или ниже кроны деревьев». При этом впечатление гармонии с окружающей средой создается путем объединения внешнего и внутреннего пространства за счет активного использования прозрачных ограждений и проникновения зеленых насаждений в виде зимних садов в пространстве медицинских и реабилитационных учреждений. Комфортные условия, создаваемые для пациента, который постоянно находится в помещении является важной частью успешного процесса выздоровления. Ведь еще в 1984 году немецкий врач Ульрих Адам обнаружил, что пациенты, которые после перенесенных операций, травм или каких-либо болезней, восстанавливаются быстрее и требуют меньше сильных медицинских препаратов, если окна в их палатах выходили на природу, чем те, чьи окна выходили на кирпичные стены [5]. Окна впускают естественное освещение, ориентируют пациентов и сотрудников на время суток, а также обеспечивает положительное эмоциональное отвлечение [6].

Озеленение и природные элементы среды воздействуют на радиационный режим, температуру, влажность и состав воздуха, на движение ветровых потоков [7]. В европейских странах и Америке, архитекторы и дизайнеры, в сотрудничестве со специалистами в области медицины такой факт взяли за основу создания объектов здравоохранения.

Примером может служить создание новой Университетской больницы в Осло, которая переехала из старого квартала в самый центр города, в новое здание, построенное за 5,7 млрд. крон или 700 млн. дол. «Это не аэрокосмические исследования», заявил Суненд Презед, британский архитектор, по поводу этого проекта. «Они только что сделали это, и сделали это гармоничным и мирным путем».

Университетская больница Акерсхус, Осло 2008 г 137000 м2 архитекторыC.F.Møller Architects (рис 1) [8].
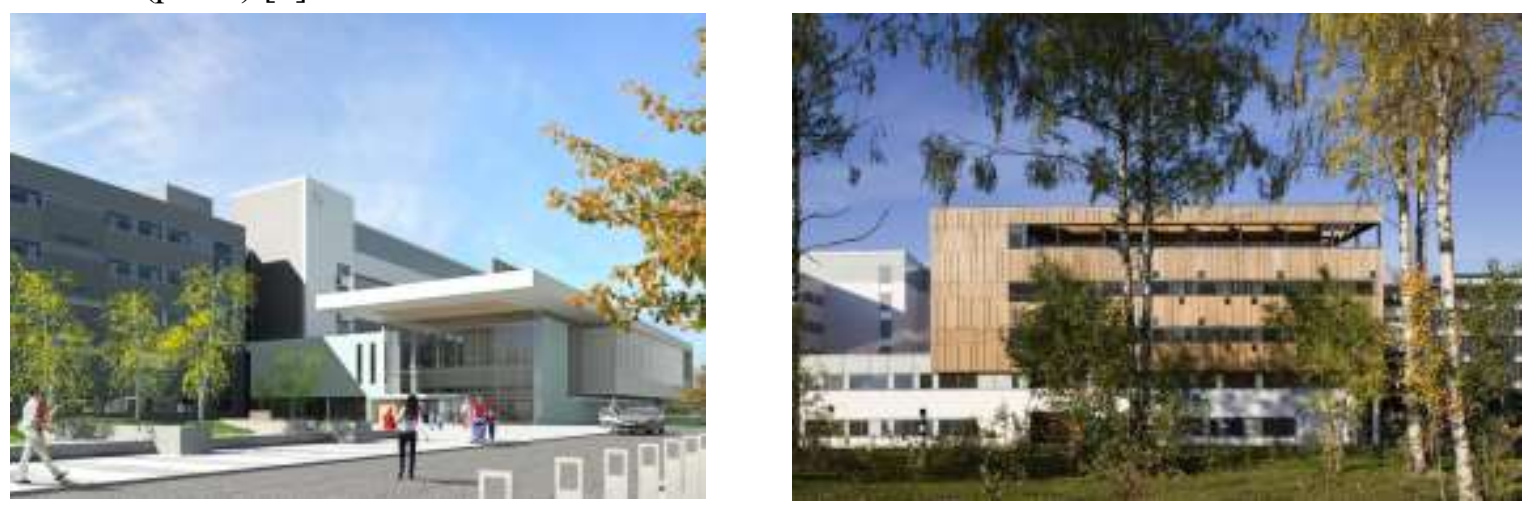

Puc. 1. 
Новая Университетская больница не является традиционной постройкой, это дружелюбное, неформальное место с открытой, хорошо структурированной обстановкой, которая представляет собой гостеприимную среду для пациентов и их семей.

Университетская больница Акерсхуса была разработана для того, чтобы подчеркнуть безопасность и ясность в обстановке, богатой опытом, где повседневные функции и хорошо известные материалы интегрированы в структуру нового здания.

Главная магистраль здания со стеклянной крышей, в которой дерево является доминирующим материалом, связывает различные здания комплекса. «Стеклянная улица» начинается в гостеприимном фойе зоны прибытия, где главная стойка регистрации принимает посетителей, и заканчивается в фойе детского отделения. Различные отделочные материалы в формировании интерьера объединены в общую композицию, в которой большие цветные панели, разработанные исландским художником Биргиром Андресоном, образуют объединяющий художественный акцент и обеспечивают «палитру» для цветовой схемы больницы.

Стеклянная улица имеет городскую структуру с общественными и полуобщественными зонами, как квадраты и открытые пространства, предлагая повседневные функции города: церковь, аптека, парикмахерская, флорист, кафе и киоск, а также транспортные узлы и другие услуги в интересах пациентов, родственников и персонала. В естественном продолжении этих функций ряд других служб, таких как медицинская информация, поликлиники и амбулаторные помещения, расположены рядом с улицей и проезжей частью.

Структура больницы дает гарантии, что пациент остается естественным центром физического плана в этом комплексе, несмотря на строгие логистические требования, которые лежат в основе всех планировки больницы. Подобно тому, как весь комплекс состоит из четких и понятных единиц, отдельные палаты построены из более мелких элементов. Палаты сосредоточены вокруг четырех так называемых внутренних двориков, которые обеспечивают четко определенную повседневную жизнь пациентов, с управляемым уровнем социальных контактов, поддерживаемым четким взаимодействием персонала. Таким образом, создается единство между природой и человеком, получается тонкий эффект прозрачности, глубины и взаимодействия с окружающей средой.

"Я бы сказал, что это лучший пример больницы из всех, что существуют на сегодняшний день, где в дизайне архитектурной среды совмещаются эмоциональные, социальные и терапевтические особенности ", сказал господин Монк, который разместил фото с этой больницей на обложке своей книги [4].

Еще одним уникальным примером природоинтегрированного подхода в проектировании объектов здравоохранения является детский госпиталь им. Нельсона Манделы построенный в 2016 г, общей площадью 30000м2 (рис 2) [9].
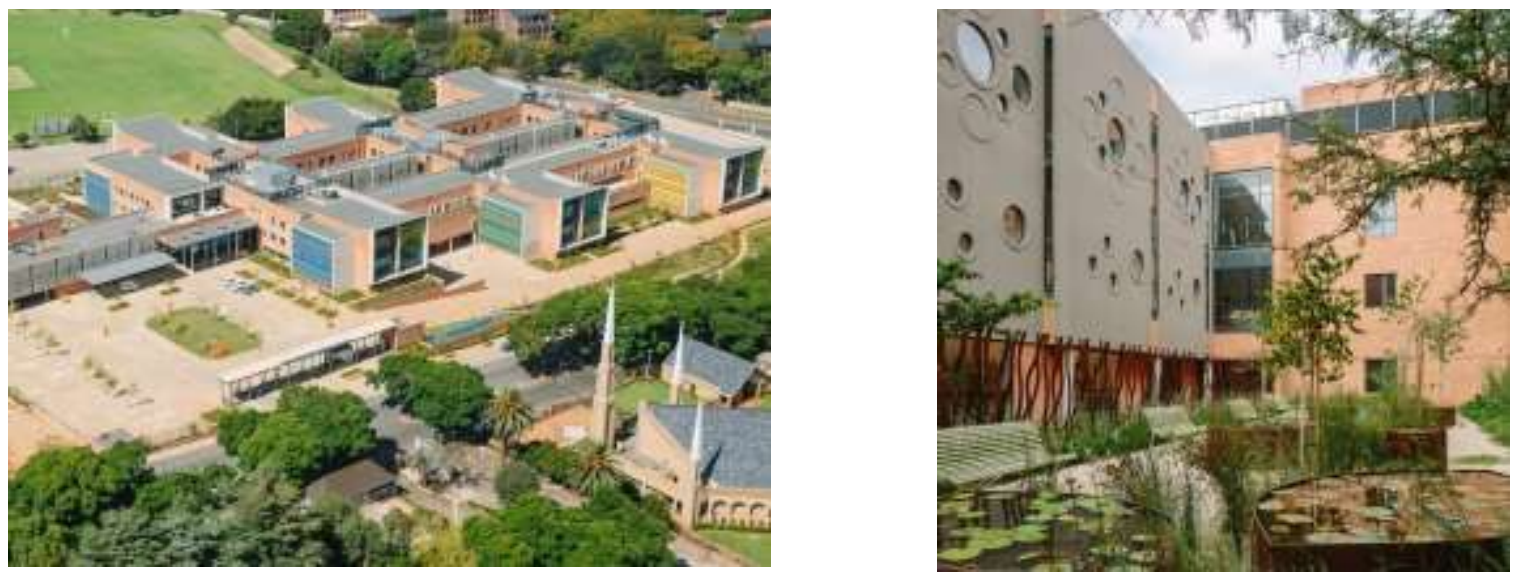

Puc. 2.

Проект представляет собой 200-местный медицинский комплекс с расширенной диагностикой и планами на будущее до 300 мест. Он будет работать в партнерстве с Медицинской школой Витватерсрандского Университета в качестве основной базы и будет взаимодействовать со всеми медицинскими учебными заведениями в регионе. В больницу входят специализированные учреждения для лечения: сердечно-сосудистых, неврологических, гематологических, онкологических, эндокринных, метаболических и почечных заболеваний. 
Проект также включает в себя оборудование для детской хирургии и в то же время поддерживает научные исследования и обучение детей.

Ключевым элементом данного задания было построить больницу, которая обеспечит высококачественное медицинское обслуживание детей в естественной среде. Этот акцент на соединении с природой является главным в формировании дизайн-проекта и станет отправной точкой в создании благоприятной, безопасной среды для детей и родителей.

Концепция Шеппарда Робсона и JCA вращается вокруг создания шести крыльев, каждое со своей медицинской специализацией. Они связаны "улицей", которая проходит через центр проекта. Эта «улица» имеет жизненно важное значение для обеспечения связи, поскольку в ней есть три основных перекрестка, которые обеспечивают эффективный поток людей. Разбивая массу здания на шесть элементов, дизайн архитектурной среды имеет домашний, человеческий масштаб, который успокаивает и знаком для детей.

Далее, удаляясь от стереотипов традиционной больницы, каждое крыло имеет свои индивидуальные отличия, которые придают им особую индивидуальность; например, цвет солнцезащитных панелей, сформированных из горизонтальных полос, изменяется для каждого отделения, подбирая яркие цвета для каждого блока. Эта композиция увеличила длину периметра здания и позволила проникнуть как можно больше естественного света, максимально использовать вид на окружающий ландшафт, а также во внутренние дворы, созданные между крыльями корпусов здания. Пять внутренних дворов и три терапевтических сада были разработаны для отдыха, трудотерапии и детских игр. Ландшафт преимущественно местный, с использованием тех видов растений, которые найдены в близлежащем природном заповеднике Мелвилл Коппи.

"Давайте называть ее "человечная больница" - больница, построенная людьми для людей", подчеркивают архитекторы, создавшие этот комплекс.

Анализируя рассмотренные примеры, становится очевидным, что формирование природоинтегрованных архитектурных объектов здравоохранения характеризуется преимуществом трех составляющих в своей структуре: экстерьер, интерьер и прилегающий ландшафт. В зависимости от взаимодействия природных элементов со структурой объекта можно выделить следующие типы формирования их архитектурной среды [1]:

- архитектурная, интерьер и ландшафт проектируются в комплексе, растительность используются во всех трех составляющих;

- экстерьер и интерьер не взаимодействуют с ландшафтом, среду формируется в структуре дома;

- экстерьер и ландшафт формируется отдельно от интерьера, растительные элементы включены во внешнюю форму объекта с окружающей средой;

- интерьер и ландшафт формируется в комплексе, среду включается в интерьер;

- экстерьер является основным природоинтегрованным элементом, среду организуется во внешней структуре здания;

- интерьер является основным природоинтегрованным элементом, среду организуется во внутренней структуре здания;

- ландшафт является основным составляющим природоинтегрованным элементом, архитектурную среду не включает растительные элементы.

Выводы. На основе проведенного исследования можно выделить несколько принципов природоинтеграции в формировании архитектурной среды объектов здравоохранения, которые зависят от функционального назначения архитектурных объектов, композиционной структуры, климатических условий, экосистемы и места расположения:

- принцип естественной интеграции включает объединение природного и архитектурного среды за счет использования прозрачных ограждающих конструкций, растительных элементов в интерьере, эко-материалов, энергосберегающих технологий формирующих экологически комфортную среду и др.;

- принцип масштабных связей архитектурных объектов с окружающей средой.

- принцип заимствования природных форм предусматривает архитектурное выражение природных закономерностей за счет морфологической подобия форм. Использования приемов имитации природных форм, пластики рельефа, заимствования конструктивных элементов;

- принцип пространственных границ определяет выражение взаимосвязи архитектурных объектов с прилегающей территорией для достижения гармонии между структурой здания и окружающей средой. 
Доказано, что формирование архитектуры объектов здравоохранения гармонично связанной с природной, окружающей средой непосредственно влияет на состояние здоровья пациентов. В процессе формирования архитектурной среды очень важно учитывать интересы пользователей среды и самой природы, для получения благоприятного результата взаимодействия природной среды и человека. Учет принципов природоинтеграции при проектировании объектов здравоохранения способствует улучшению качества среды учреждений медицины и реабилитации, повышения уровня предоставляемых услуг и гармонизации окружающей среды.

\section{ЛИТЕРАТУРА}

1. Гордиенко Ю. Принципы формирования природоинтегрированной архитектуры. - Рукопись.

2. Фоменко Н.А. Природа как основа архитектуры // Технические науки - от теории к практике: сб. ст. по матер. XXIX междунар. научно-практической. конф. № 12 (25). - Новосибирск: СибАК 2013.

3. Мастера архитектуры об архитектуре. - М.: Искусство, 1972.

4. Tony Monk Hospital Builders 224 pages John Wiley and Sons Ltd 2004

5. http://medbusiness.ru/upload/img/giprozdrav.pdf

6. http://news.fraserhealth.ca/News/July-2014/Integrating-nature-into-the-healing-process-Nature.aspx

7. https://www.archdaily.com/36473/akershus-university-hosptial

8. http://rbcreative.ru/news-world/472-universitetskaya-klinika-akersxus-v-norvegii.html

9. https://www.nelsonmandelachildrenshospital.org/ 